\title{
Impact of strenuous exercise on bone metabolism parameters among elderly
}

\author{
Walaa W. Aly ${ }^{*}$, Rehab R. Desouki ${ }^{1}$, Ayman M. Abdel-Mottaleb ${ }^{2}$ and Hala S. Sweed ${ }^{1}$ \\ ${ }^{1}$ Geriatric and Gerontology Department, Faculty of Medicine, Ain Shams University, Egypt \\ ${ }^{2}$ Cardiology Department, Faculty of Medicine, Ain Shams University, Egypt
}

\begin{abstract}
Background: Physical activity is known to increase average life expectancy and decrease the risk of development and progression of most chronic degenerative disease states. Strenuous physical activities are found to be associated with a reduced risk of coronary heart disease (CHD) and a significant improvement in glucose control and insulin sensitivity while physical activities of lower intensities were not. However, strenuous exercise was found to increase bone resorption, without a concomitant increase in formation in young adults rendering the bone vulnerable to fracture but there is lack of data supporting these findings among healthy aged population.
\end{abstract}

Objective: To assess the effect of strenuous exercise on bone metabolism in elderly individuals.

Method: A cross sectional study conducted from the first of March to the end of July, 2014, where 40 elderly attended the Geriatric outpatient clinic at that time were included. They underwent full medical examination, electrocardiogram (ECG), measurement of Serum parathyroid hormone (PTH), alkaline phosphatase (ALP), ionized calcium and urinary calcium. The participants answered a physical activity questionnaire specifically adapted for the elderly and underwent a session of strenuous exercise with mean duration of $10.6 \pm 2.6$ minutes aiming at reaching $70-85 \%$ of the participant's maximum heart rate.

Results: Serum PTH, serum ALP and urinary Ca were significantly elevated while serum ionized Ca was significantly reduced in relation to the performed exercise.

Conclusion: In elderly subjects, strenuous exercise disturbed calcium homeostasis and bone related hormones. Further studies are needed to assess the long-term effect of strenuous exercise on the elderly and for planning a safe exercise program for them.

\section{Introduction}

Aging is considered a risk factor for the development and progression of many chronic diseases including cardiovascular disease, type 2 diabetes, obesity [1] and most chronic degenerative disease states such as arthritis and osteoporosis. However, physical activity substantially modifies this risk [2]. In addition, physical activity participation reduces risk of falls and fall-related injuries, and prevents or delays functional and mobility limitations in older adults [3]. However, recommending specific amounts of activity for older people remains a conflicting issue because of the large variation in the ageing process and the capacity to engage in physical activity because of disabilities [4]. Vigorous physical activities, with a relative intensity equivalent of $70-85 \%$ of maximum heart rate [5], was found to be associated with a reduced risk of coronary heart disease (CHD), whereas, physical activities of lower intensities were not [6,7]. Improvements in glucose control or insulin sensitivity were found among healthy subjects who exercised at vigorous intensities but not at moderate intensities [8]. While, physical inactivity [9] or prolonged immobilization [10] lead to destructive bone loss, bone formation dramatically increases when immobilized subjects resume exercise [11]. This has led to the popular conclusion that physical activity enhances bone formation and, consequently, bone mineral density (BMD) [12]. Despite previously mentioned benefits of physical exercise, adverse effects were noted as regarding high intensity exercise [13] as it was found to increase bone resorption in young adults, without a concomitant increase in formation reflecting an alteration to the bone remodeling balance rendering the bone vulnerable to further mechanical stresses and fracture [14]. However, few reports are available concerning the effects of physical exercise on bone in a healthy aged population [15]. So, this study was designed to assess the effect of strenuous exercise on bone metabolism in elderly individuals.

The state of the skeleton can be evaluated by many techniques, of which biochemical markers exhibit the fastest response to intervention while being minimally invasive [16]. Serum markers of bone metabolism such as alkaline phosphatase (ALP), calcium, and phosphorous can be used to study dynamic changes in bones and their metabolic response to physical activity [17]. However, the immediate effect of exercise on calcium homeostasis and bone turnover was not sufficiently evaluated in elderly population; even though the data obtained from bone marker based studies would provide useful information for the design of therapeutic programs to improve bone health [18].

The aim of the current study was to determine to what extent a single session of brisk walking exercise can affect bone metabolism related hormones in elderly subjects. Brisk walking is generally not considered to be a high impact loading activity, but it is the only physical exercise commonly practiced by the elderly.

Correspondence to: Walaa W. Aly, Ain Shams University Hospitals, Geriatric and Gerontology department, Abbassia square, Cairo, Egypt, Tel: +201005296077; E-mail: walaawessam@yahoo.com

Key words: strenuous exercise, bone metabolism, elderly

Received: July 22, 2017; Accepted: August 28, 2017; Published: August 31, 2017 


\section{Methods}

\section{Study design: A cross sectional study.}

Setting: Geriatric outpatient clinic, Ain Shams University Hospital.

Study participants: Forty participants aged 60-80 years recruited from the outpatient clinics in Ain Shams university hospital from the first of March to the end of July, 2014. The Exclusion criteria were inability to perform the exercise, history of coronary artery disease, medical treatment and medical conditions known to affect bone metabolism e.g.: Cushing syndrome, chronic kidney disease, steroids, long term use of proton pump inhibitors to exclude their effect on parameters measured in the study.

The study was approved by the ethical committee of the Faculty of Medicine, Ain Shams University. Written consent was obtained from every participant after explanation of the study aim and procedures. All subjects participating in the study were subjected to the following: Full history taking, physical examination, and an electrocardiogram. The subjects were asked to complete a questionnaire concerning their physical activity level. This questionnaire is specifically adapted for the elderly with different scores to quantify household, sports, and other physically active leisure time activities, together resulting in a total activity score. The questionnaire provided a method for classifying elderly subjects into categories of high, medium, and low physical activity, with cut off points of 16.5 and 9.4 [19].

Exercise regimen: Each of the participants underwent a session of strenuous exercise with mean duration of $10.6 \pm 2.6$ minutes aiming at reaching $70-85 \%$ of the participant's maximum heart rate (maximum heart rate $=220$-age) . Exercise was performed on a treadmill connected to a monitor reflecting continuous ECG monitoring for early detection of possible ischemic changes. It started with 3 minutes of warm up at mild intensity exercise ( $40 \%$ of calculated maximum heart rate) followed by gradual increase of exercise intensity reflected as a gradual increase in heart rate till reaching approximately $75-85 \%$ of calculated maximum heart rate and ended with 3 minutes of cooling down with gradual decrease in exercise intensity till reaching basal heart rate of the participant prior to exercise. The participants were supervised for signs of termination of exercise such as dyspnea, cyanosis or pallor, chest pain, fatigue, or stoppage upon request. Monitoring for pulse \& blood pressure throughout the session was performed. Vital data were measured again during five minutes following exercise session.

Sample collection and biochemical assay: Two venous blood and two urine samples were obtained from each participant by sterile disposable equipment under aseptic conditions, none of the participants was fasting during sample collection. First urine and blood samples were obtained at complete physical and mental rest of at least 30 minutes while second samples were obtained within 10-30 seconds after performing the standard exercise. Each blood sample underwent measurement of parathyroid hormone (PTH), alkaline phosphatase (ALP) and ionized calcium while urine samples underwent measurement of calcium.

DIAsource hPTH-EASIA Kit was used for immunometric assay for PTH. It is a solid phase Enzyme Amplified Sensitivity Immunoassay performed on microtiterplates. Immunometric assays (2nd generation) are based on the recognition of PTH by two different antibodies, one carboxyl terminal and the other amino terminal specific [20].

Stanbio Alkaline Phosphatase LiquiColor ${ }^{\circledR}$ kit was used for quantitative determination of alkaline phosphatase in serum. Stanbio
Alkaline Phosphatase procedure measures serum ALP activity by a kinetic method using 4-nitrophenyl phosphate as substrate. Alkaline Phosphatase hydrolyzes 4-nitrophenyl phosphate to form 4nitrophenol and phosphates. 4-nitrophenol is yellow in color, at PH 10.4 with an absorbance peak at $405 \mathrm{~nm}$. The rate at which 4-nitrophenol is formed is directly proportional to alkaline phosphatase activity [21].

Cayman's calcium assay kit was used to determine total calcium level both in serum and urine. The assay utilizes an optimized variant of the o-Cresolphthalein -calcium reaction in which a vivid purple complex is formed in the presence of calcium. The intensity of the color is directly proportionate to the concentration of calcium in the sample [22].

\section{Statistical analysis}

Statistical presentation and analysis of the present study was conducted, using the mean, standard error, student t- test, Chi-square, Linear Correlation Coefficient and Analysis of variance [ANOVA] tests by SPSS 17.

Chi-square test was to test the association between categorical variables. the hypothesis that the row and column variables are independent, without indicating strength or direction of the relationship. Pearson chi-square and likelihood-ratio chi-square. Fisher's exact test and Yates' corrected chi-square are computed for $2 \times 2$ tables.

Linear Correlation coefficient was used for detection of correlation between two quantitative variables in one group.

ANOVA test was used for comparison among different times in the same group in quantitative data.

\section{Results}

The study was conducted on 40 elderly; 26 males representing $65 \%$ of the studied group and 14 females representing $35 \%$. The age of participants ranges from $60-80$ years old with mean age of $66.17 \pm 6.33$ years. $77.5 \%$ were non-smokers. $22 \%$ of the study population $(n=9)$ scored $<9.5$ in the physical activity questionnaire representing low level of physical activity while 50\% ( $n=20)$ scored 9.5-16 representing moderate level of physical activity and finally $28 \%(\mathrm{n}=11)$ scored $>16.5$ representing high level of physical activity. Duration of exercise performed ranges from 7-15 minutes with mean duration of $10.6 \pm 2.6$ minutes (Table 1)

The mean serum PTH, serum ALP and urinary Ca were significantly elevated after the performed exercise $(\mathrm{p}<0.001)$, while serum ionized $\mathrm{Ca}$ was significantly reduced in relation to the performed exercise $(\mathrm{p}<0.001)$. (Table 2)

There is statistically significant difference between the 3 groups of basal activity levels as regard percentage of increase in urinary calcium excretion in relation to exercise as the higher basal activity level of the participant, the less the percentage of increase in urinary calcium excretion in relation to exercise $(\mathrm{p}=0.03)$ (Table 3$)$

This study found that the increase in urinary calcium in relation to exercise was inversely related to both exercise duration and basal physical activity (according to questionnaire score) of the participants and that the increase in serum PTH in relation to exercise was inversely related to basal physical activity of the participants.

The decrease in serum ionized calcium in relation to exercise was directly related to age of the participants while the increase in heart rate in relation to exercise was inversely related to both age and basal pulse (Table 4) 
Table 1. Characteristics of the study participants.

\begin{tabular}{|c|c|c|}
\hline Parameters & Range & Mean \pm SD \\
\hline Age & $60-80$ & $66.18 \pm 6.33$ \\
\hline Questionnaire score & $3-22$ & $12.98 \pm 4.83$ \\
\hline Body weight & $62-81$ & $71 \pm 5.5$ \\
\hline Height & $168-174$ & $163.64 \pm 26.44$ \\
\hline BMI & $21.96-29.74$ & $25.24 \pm 2.15$ \\
\hline systolic blood pressure & $100-160$ & $124 \pm 11.95$ \\
\hline diastolic blood pressure & $60-80$ & $75.5 \pm 6.39$ \\
\hline Pulse & $60-95$ & $75 \pm 9.7$ \\
\hline Exercise duration & $7-15$ & $10.6 \pm 2.6$ \\
\hline
\end{tabular}

Table 2. Relation between heart rate and biochemical parameter levels and the exercise performed.

\begin{tabular}{|c|c|c|c|c|c|}
\hline \multirow{2}{*}{\multicolumn{2}{|c|}{ Parameters }} & \multirow{3}{*}{$\begin{array}{c}\text { Before } \\
\text { exercise }\end{array}$} & \multirow{3}{*}{$\begin{array}{c}\begin{array}{c}\text { After } \\
\text { exercise }\end{array} \\
95-141\end{array}$} & \multicolumn{2}{|c|}{ Paired $t$ test } \\
\hline & & & & $\mathbf{t}$ & P-value \\
\hline \multirow{2}{*}{ Heart rate } & Range & & & \multirow{2}{*}{-23.83} & \multirow{2}{*}{$<0.001$} \\
\hline & Mean \pm SD & $74.56 \pm 10.28$ & $124.13 \pm 10.38$ & & \\
\hline \multirow{2}{*}{ PTH } & Range & $39-90$ & $43-98$ & \multirow{2}{*}{-14.43} & \multirow{2}{*}{$<0.001 *$} \\
\hline & Mean \pm SD & $62.9 \pm 9.55$ & $73.15 \pm 11.8$ & & \\
\hline \multirow{2}{*}{ ALP } & Range & $33-96$ & $35-117$ & \multirow{2}{*}{-9.83} & \multirow{2}{*}{$<0.001 *$} \\
\hline & Mean \pm SD & $63.76 \pm 19.24$ & $75.4 \pm 21.9$ & & \\
\hline \multirow{2}{*}{ Ionized Ca } & Range & $3.5-5.2$ & $3.35-5$ & \multirow{2}{*}{17.78} & \multirow{2}{*}{$<0.001 *$} \\
\hline & Mean \pm SD & $4.35 \pm 0.44$ & $4.14 \pm 0.44$ & & \\
\hline \multirow{2}{*}{ Urinary Ca } & Range & $3.8-9$ & $4.2-9.7$ & \multirow{2}{*}{-15.11} & \multirow{2}{*}{$<0.001$} \\
\hline & Mean \pm SD & $6.47 \pm 1.5$ & $6.91 \pm 1.62$ & & \\
\hline
\end{tabular}

Table 3. Relation between basal physical activity and percentage of change in biochemical parameter levels in response to exercise.

\begin{tabular}{|c|c|c|c|c|c|}
\hline \multirow{2}{*}{$\%$ of change } & Low & Moderate & High & \multicolumn{2}{|c|}{ ANOVA } \\
\cline { 2 - 6 } & Mean \pm SD & Mean \pm SD & Mean \pm SD & F & P-value \\
\hline HR & $66.45 \pm 19.72$ & $65.85 \pm 24.44$ & $77.10 \pm 28.28$ & 0.81 & 0.45 \\
\hline PTH & $19.56 \pm 9.89$ & $16.14 \pm 5.29$ & $13.78 \pm 4.91$ & 1.97 & 0.15 \\
\hline ALP & $31.04 \pm 43.28$ & $18.21 \pm 6.01$ & $13.61 \pm 5.12$ & 1.87 & 0.17 \\
\hline Ionized Ca & $5.39 \pm 1.48$ & $5.14 \pm 1.57$ & $3.92 \pm 1.87$ & 2.58 & 0.09 \\
\hline Urinary Ca & $7.97 \pm 1.21$ & $6.73 \pm 1.91$ & $5.54 \pm 2.30$ & 4.08 & $\mathbf{0 . 0 3}$ \\
\hline
\end{tabular}

HR : Heart rate; PTH: Parathyroid hormone; ALP: Alkaline phosphatase; Ca: Calcium

Table 4. Correlation between age, questionnaire score, BMI, blood pressure, pulse, exercise duration, heart rate and biochemical parameter levels.

\begin{tabular}{|c|c|c|c|c|c|c|}
\hline Parameters & & HR \% & РРТН \% & AALP \% & $\begin{array}{c}\text { Ionized } \\
\mathrm{Ca} \%\end{array}$ & $\begin{array}{c}\text { Urinary } \\
\text { Ca } \%\end{array}$ \\
\hline \multirow{2}{*}{ Age } & $\mathbf{r}$ & -0.42 & -0.14 & -0.18 & 0.32 & 0.2 \\
\hline & P-value & 0.007 & 0.379 & 0.262 & 0.042 & 0.226 \\
\hline \multirow{2}{*}{$\begin{array}{l}\text { Questionnaire } \\
\text { score }\end{array}$} & $\mathbf{r}$ & 0.13 & -0.32 & -0.31 & -0.3 & -0.35 \\
\hline & P-value & 0.416 & 0.041 & 0.055 & 0.062 & 0.027 \\
\hline \multirow{2}{*}{ BMI } & $\mathbf{r}$ & -0.03 & 0.03 & 0.21 & -0.14 & 0.04 \\
\hline & P-value & 0.857 & 0.859 & 0.195 & 0.382 & 0.802 \\
\hline \multirow{2}{*}{$\begin{array}{l}\text { Systolic blood } \\
\text { pressure }\end{array}$} & $\mathbf{r}$ & -0.02 & 0.2 & 0.06 & 0.14 & 0.17 \\
\hline & P-value & 0.914 & 0.222 & 0.722 & 0.385 & 0.298 \\
\hline \multirow{2}{*}{$\begin{array}{l}\text { Diastolic blood } \\
\text { pressure }\end{array}$} & $\mathbf{r}$ & -0.15 & 0.17 & 0.19 & 0.11 & 0.18 \\
\hline & P-value & 0.345 & 0.303 & 0.236 & 0.515 & 0.277 \\
\hline \multirow{2}{*}{ Pulse } & $\mathbf{r}$ & -0.78 & -0.09 & 0.01 & 0.07 & 0.12 \\
\hline & P-value & 0.000 & 0.586 & 0.971 & 0.674 & 0.448 \\
\hline \multirow{2}{*}{$\begin{array}{l}\text { Exercise } \\
\text { duration }\end{array}$} & $\mathbf{r}$ & 0.29 & 0.18 & -0.06 & -0.04 & -0.32 \\
\hline & P-value & 0.067 & 0.268 & 0.718 & 0.820 & 0.046 \\
\hline
\end{tabular}

\section{Discussion}

Physical exercise has been shown to decrease mortality and agerelated morbidity in older adults, including improvements in blood pressure, diabetes, lipid profile, osteoarthritis, osteoporosis, and neurocognitive function. Regular physical exercise is also associated with decreased mortality and age-related morbidity in older adults [3]. However, adverse effects of physical activity must be taken into consideration especially chronic sustained high intensity exercise as it was found to increase bone resorption in young adults [14] with less sufficient data concerning the effect of physical exercise on bone in a healthy aged population [15].

The current study was conducted to assess the effect of a single session of strenuous exercise on bone metabolism in elderly individuals. It showed that a single session of strenuous exercise induced a significant variation in the parameters of calcium homeostasis. As serum PTH, serum ALP and urinary Ca were significantly elevated in relation to the performed exercise while serum ionized Ca was significantly reduced in relation to the performed exercise.

The increase in urinary calcium excretion after a single session of strenuous exercise could be due to a decrease in renal calcium reabsorption as a result of exercise induced metabolic acidosis. The imbalance between urinary $\mathrm{Ca}$ excretion and $\mathrm{Ca}$ release from bone may induce a net decrease in serum ionized calcium (iCa) level [23]. The rise in serum PTH level can be the result of the decrease in serum $\mathrm{iCa}$ level, the main regulating factor of PTH secretion as there is a strong relationship between extracellular iCa concentration and PTH secretion [24]. In addition, acidosis may also have a direct effect on the increase in PTH secretion independently of calcium level [25].

These results were, nevertheless, in agreement with those of Bouassida et al. [26] who found a decrease in ionized Ca levels and a rise in PTH levels in subjects during continuous exercise at 70 and $80 \%$ of Vo2max. These findings were also observed by Nishiyama et al. [27] in athletic and non-athletic young men after short and moderately intense exercise.

Maïmoun et al., [28] studied PTH responses before and following a maximal incremental exercise test in elderly men and women and noted that PTH concentrations were increased after the exercise and that this increase could have an anabolic action on bone turnover.

Similar to the current study, Thorsen et al., [29] observed a reduction of plasma ionized calcium at 1 and 72 hours and an increase of PTH concentrations at 24 and 72 hours after endurance exercise (45 minutes running at $45 \%$ of maximal oxygen uptake $\left[\mathrm{VO}_{2} \mathrm{max}\right]$ ) among young women.

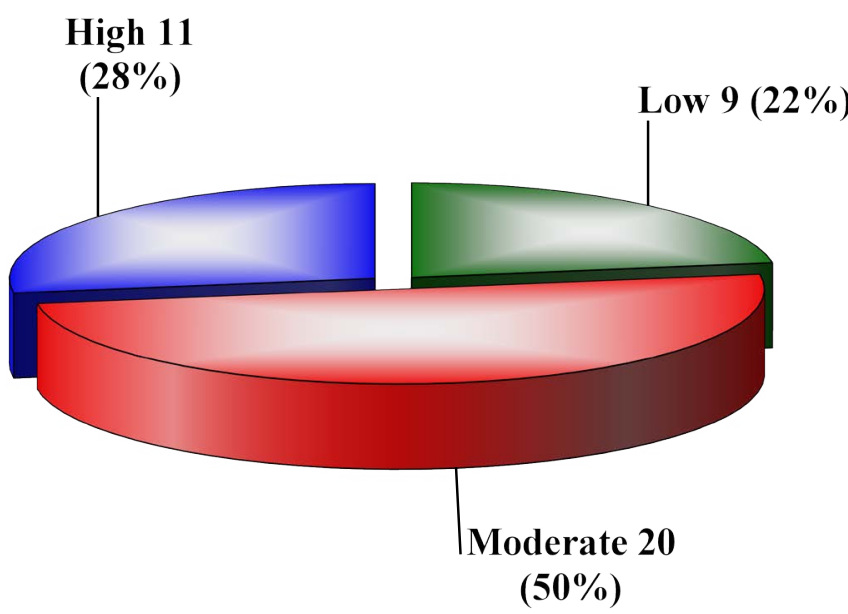

Figure 1. Distribution of the study population according to basal level of physical activity measured by physical activity questionnaire. 
In contrast, Kristoffersson et al., [30] found increased iCa levels after short term maximal work, without significant changes in the serum PTH levels.

The current results were in accordance with other studies that have investigated the immediate response of bone markers to short and intense or moderate exercise bouts [31,32].

Significant elevation in serum ALP in response to the performed exercise is considered to reflect newly synthesized bone. Physical activity makes ALP exert anabolic effects on bone metabolism on one hand, and on the other, increases calcium reserves in bones [33].

Similarly, Rudberg et al., [34] reported an increase in ALP levels after 30 -40 minutes of moderate running and Wallace et al., [35] found the same results after 2 hours of pedaling at $80 \%$ of VO2 max.2 However Ashizawa et al. [36] observed a decrease in ALP, 2 to 3 days after weight training. On the other hand, one study showed that shortterm exercise has no effect on biochemical bone markers [30].

The study also found a negative correlation between basal activity levels of the participants; measured by physical activity questionnaire and the response of urinary $\mathrm{Ca}$ to strenuous exercise as its elevation in response to exercise was less in participants with higher basal activity level. This can be explained by the fact that regular physical activity is known to increase vitamin $\mathrm{D}$ on the long run resulting in increased renal reabsorption of calcium and subsequently decreases its excretion [37]. These findings suggest that regular physical activity maintains serum calcium level through decreasing its excretion rather than reverting to bone demineralization explaining less urinary calcium loss in those with higher basal level of physical activity among study participants.

The conducted study assessed the effect of single session of strenuous exercise on bone metabolism; assessment of effect of long term strenuous exercise on bone metabolism, and subsequently bone mass, on the long run is therefore needed.

One of the draw backs of the study is that strict exclusion criteria were carried out to ensure safety of the participants during performing strenuous exercise and also to avoid medical conditions or medications affecting the biochemical parameters measured, this resulted in absence of frail elderly from study population.

\section{References}

1. Singh MA (2004) Exercise and aging. Clin Geriatr Med 20: 201-221. [Crossref]

2. Peeters G, Dobson AJ, Deeg DJ, Brown WJ (2013) A life-course perspective on physical functioning in women. Bull World Health Organ 91: 661-670. [Crossref]

3. Nelson ME, Rejeski WJ, Blair SN (2007) Physical activity and public health in older adults: recommendation from the American College of Sports Medicine and the American Heart Association. Med Sci Sports Exerc 39: 1435-1445.

4. Taylor AH, Cable NT, Faulkner G (2004) Physical activity and older adults: a review of health benefits and the effectiveness of interventions. Journal of Sports Sciences 22: 703-725.

5. Norton K, Norton L, Sadgrove D (2010) Position statement on physical activity and exercise intensity terminology. J Sci Med Sport 13: 496-502. [Crossref]

6. Lee IM, Sesso HD, Oguma Y, Paffenbarger RS Jr (2003) Relative intensity of physical activity and risk of coronary heart disease. Circulation 107: 1110-1116. [Crossref]

7. Yu S, Yarnell JW, Sweetnam PM (2003) What level of physical activity protects against premature cardiovascular death? The Caerphilly study. Heart 89: 502-506.

8. Colberg SR, Hernandez MJ, Shahzad F (2013) Blood glucose responses to type, intensity, duration, and timing of exercise. Diabetes Care 36: e177.

9. Feskanich D, Flint AJ, Willett WC (2014) Physical activity and inactivity and risk of hip fractures in men. Am J Public Health 104: e75-81. [Crossref]
10. Garland DE, Adkins RH, Stewart CA (2008) Five-year longitudinal bone evaluations in individuals with chronic complete spinal cord injury. J Spinal Cord Med 31: 543550. [Crossref]

11. Marcus R (2008) Mechanisms of exercise effects on bone. In: Principles of Bone Biology (3rd Ed.). Edited by Bilezikian JP, Raisz LG, Martin TJ, San Diego CA, Academic Press 1135-1146.

12. Vainionpaa A, Korpelainen R, Vihriala E (2006) Intensity of exercise is associated with bone density change in premenopausal women. Osteoporosis International 17: 455-463.

13. Dua JS, Cooper AR, Fox KR, Stuart AG (2009) Exercise: the neglected risk factor and the neglected treatment. Heart 95: 1278. [Crossref]

14. Guillemant J, Accarie C, Peres G (2004) Acute effects of an oral calcium load on markers of bone metabolism during endurance cycling exercise in male athletes. Calcified Tissue Intern 74: 407-414.

15. Sartorio A, Lafortuna C, Capodaglio P (2001) Effects of a 16 week progressive highintensity strength training (HIST) on indexes of bone turnover in men over 65 years: a randomised controlled study. J Endocrinol Invest 24: 882-6.

16. Rantalainen T, Heinonen A, Linnamo V (2009) Short-term bone biochemical response to a single bout of high-impact exercise. J Sports Sci Med 8: 553-559.

17. Komnenou A, Karayannopoulou M, Polizopoulou ZS (2005) Correlation of serum alkaline phosphatase activity with the healing process of long bone fracture in dogs. Veterinary Clinical Pathology 34: 35-38.

18. Maimoun L, Simar D, Malatesta D (2005) Response of bone metabolism related hormones to a single session of strenuous exercise in active elderly subjects. Br J Sports Med 39: 497-502.

19. Voorrips LE, Ravelli AC, Dongelmans PC, Deurenberg P, Van Staveren WA (1991) A physical activity questionnaire for the elderly. Med Sci Sports Exerc 23: 974-979. [Crossref]

20. Bouillon R, Coopmans W, Degroote DE (1990) Immunoradiometric assay of parathyrin with polyclonal and monoclonal region-specific antibodies. Clin Chem 36: 271-276.

21. Bowers GN Jr, McComb RB (1966) A continuous spectrophotometric method for measuring the activity of serum alkaline phosphatase. Clin Chem 12: 70-89. [Crossref]

22. Kratochvil B, Xi-Wen He (1991) A Study of Ca2+-Arsenazo III System and Its Applications to the Spectrophotometric Determination of Free Calcium in Solution Can J Chem 68: 1932-1936.

23. Ashisawa N, Fujimura R, Tokuyama K (1997) A bout of resistance exercises increases urinary calcium independently of osteoclastic activation in men. J Appl Physiol 83: $1159-63$

24. Brent GA, Leboff MS, Seely EW (1988) Relation between the concentration and rate of change of calcium and serum intact parathyroid hormone levels in normal humans. $J$ Clin Endocrinol Metab 67: 944-950.

25. Lopez I, Aguilera-Tejero E, Felsenfeld AJ (2002) Direct effect of acute metabolic and respiratory acidosis on parathyroid hormone secretion in the dog. $J$ Bone Miner Res 17: 1691-700.

26. Bouassida A, Zalleg D, Zaouali-Ajina M (2003) Parathyroid hormone concentrations during and after two periods of high intensity exercise with and without an intervening recovery period. Euro J of Applied Physiol 88: 339-344.

27. Nishiyama S, Tomoeda S, Ohta T (1988) Differences in basal and post-exercise osteocalcin levels in athletic and nonathletic humans. Calcif Tissue Int 43:150-154.

28. Maimoun L, Simar D, Malatesta D (2005) Response of bone metabolism related hormones to a single session of strenuous exercise in active elderly subjects. Br J Sports Med 39: 497-502.

29. Thorsen K, Kristoffersson A, Hultdin J (1997) Effects of moderate endurance exercise on calcium, parathyroid hormone, and markers of bone metabolism in young women. Calcif Tissue Inter 60: 16-20.

30. Kristoffersson A, Hultdin J, Holmlund I, Thorsen K, Lorentzon R (1995) Effects of short-term maximal work on plasma calcium, parathyroid hormone, osteocalcin and biochemical markers of collagen metabolism. Int J Sports Med 16: 145-149. [Crossref]

31. Maïmoun L, Manetta J, Couret I, Dupuy AM, Mariano-Goulart D, et al. (2006) The intensity level of physical exercise and the bone metabolism response. Int J Sports Med 27: 105-111. [Crossref] 
32. Lester ME, Urso ML, Evans RK (2009) Influence of exercise mode and osteogenic index on bone biomarker responses during short-term physical training. Bone 45: 768776.

33. Terreni A, Pezzati P (2012) Biochemical markers in the follow-up of the osteoporotic patients. Clin Cases Miner Bone Metab 9: 80-84. [Crossref]

34. Rudberg A, Magnusson P, Larsson L, Joborn H (2000) Serum isoforms of bone alkaline phosphatase increase during physical exercise in women. Calcif Tissue Int 66 : 342-347. [Crossref]
35. Wallace JD, Cuneo RC, Lundberg PA (2000): Responses of markers of bone and collagen turnover to exercise, growth hormone $(\mathrm{GH})$ administration, and $\mathrm{GH}$ withdrawal in trained adult males. $J$ of ClinEndocr and Metab 85:124-133.

36. Ashizawa N, Ouchi G, Fujimura R, Yoshida Y, Tokuyama K, et al. (1998) Effects of a single bout of resistance exercise on calcium and bone metabolism in untrained young males. Calcif Tissue Int 62: 104-108. [Crossref]

37. Foo LH, Zhang Q, Zhu K (2009) Relationship between vitamin D status, body composition and physical exercise of adolescent girls in Beijing. Osteoporos Int 20: 417-25.

Copyright: (C2017 Aly WW. This is an open-access article distributed under the terms of the Creative Commons Attribution License, which permits unrestricted use, distribution, and reproduction in any medium, provided the original author and source are credited. 